\title{
Discussion: Potential damage assessment in buildings undergoing tilt
}

Eshagh Namazi

PhD student, Steel Technology Centre, Universiti Teknologi Malaysia, Malaysia

\section{Hisham Mohamad}

Senior lecturer, Faculty of Civil Engineering, Universiti Teknologi Malaysia, Malaysia
Benoit D. Jones MEng, EngD, CEng, MICE

Principal teaching fellow, Tunnelling and Underground Space MSc, School of Engineering, University of Warwick, UK

\section{Contribution by B. Jones}

The authors (Namazi and Mohamad, 2010) have provided an elegantly derived solution to the problem of accounting for tilt in damage assessments. However, the solution depends on the assumption that the side of the building at the top of the settlement-induced slope is fixed, while the side of the building at the bottom of the slope is completely free to move (see Figure 2 of the original paper). This intuitively seems unrealistic if the
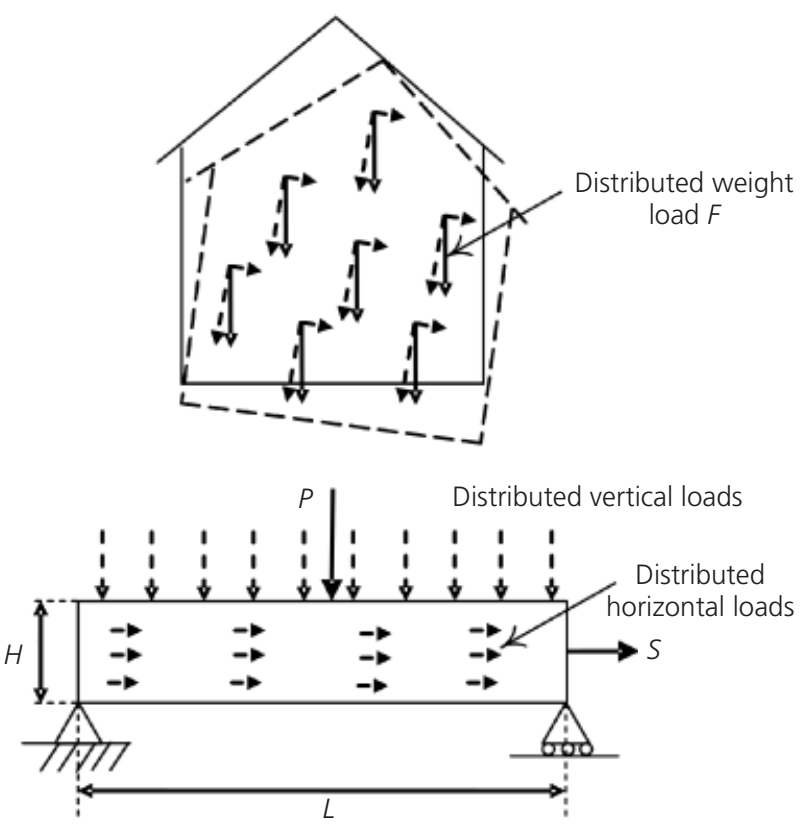

Figure 2. Analogy of tilted building with simply supported beam foundation details are similar, and although the assumption allows strains to be caused by tilt, no horizontal strains would be transferred to the building from the ground if it were true. It would be more appropriate to assume that both sides are fixed in relation to the ground, as current methods do. If both sides are fixed, no additional strains are caused by tilt, but horizontal strains in the ground induce horizontal strains in the building. Could the authors provide evidence to show that the assumption illustrated by Figure 2 is valid?

\section{Authors' reply}

In the tilted building, the model considers the horizontal component of the self-weight as the activating force (uniformly distributed) to induce horizontal strain within the structure and assumes the immediate soils below the foundation to be displaced elastically by the same amount. Such a notion may be acceptable, considering the resistance force (e.g. shear stiffness) provided by the soils is very small in comparison to the stiffness of the structure (e.g. Liu and Ma, 2013). Conversely, the foundation may act as the resistance to the 'active' excavation-induced ground displacements below. In this case, the measured horizontal strain (assuming linearly distributed ground displacement) is usually smaller owing to the inherent stiffness of the structure. The horizontal strains from these two components may be superimposed on the overall tensile strains calculation as expressed previously in Equations 14 and 15. It must be noted that the onset of visible cracking associated with the maximum horizontal tensile strain is not sensitive to the mode of beam supports. As shown in Figure 7, under a uniformly distributed axial load, both beams with fixed-fixed and fixed-free end conditions yield similar maximum tensile strains, albeit the fixed-fixed ends having an elongation of only half the length of the building, which is rather unrealistic. 


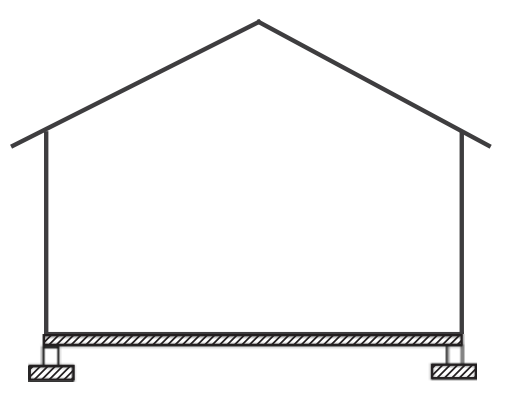

Distributed horizontal load, $S$
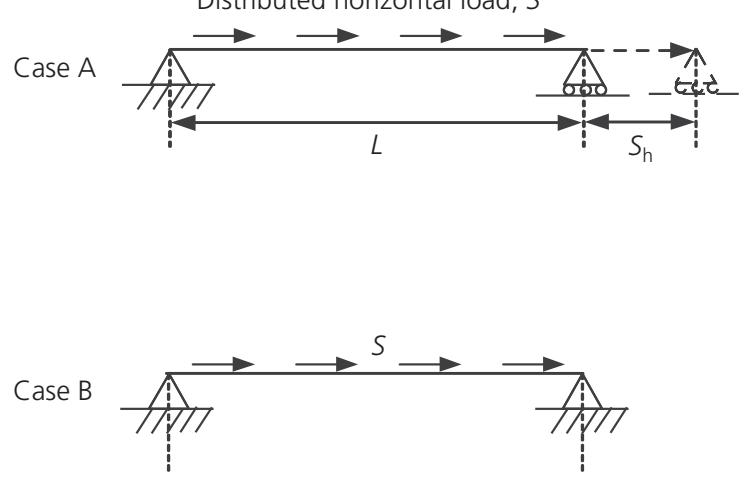

Figure 7. Horizontal strain profiles of simply supported beams under distributed horizontal load. Case A shows fixed-free end conditions and case B shows fixed-fixed end conditions
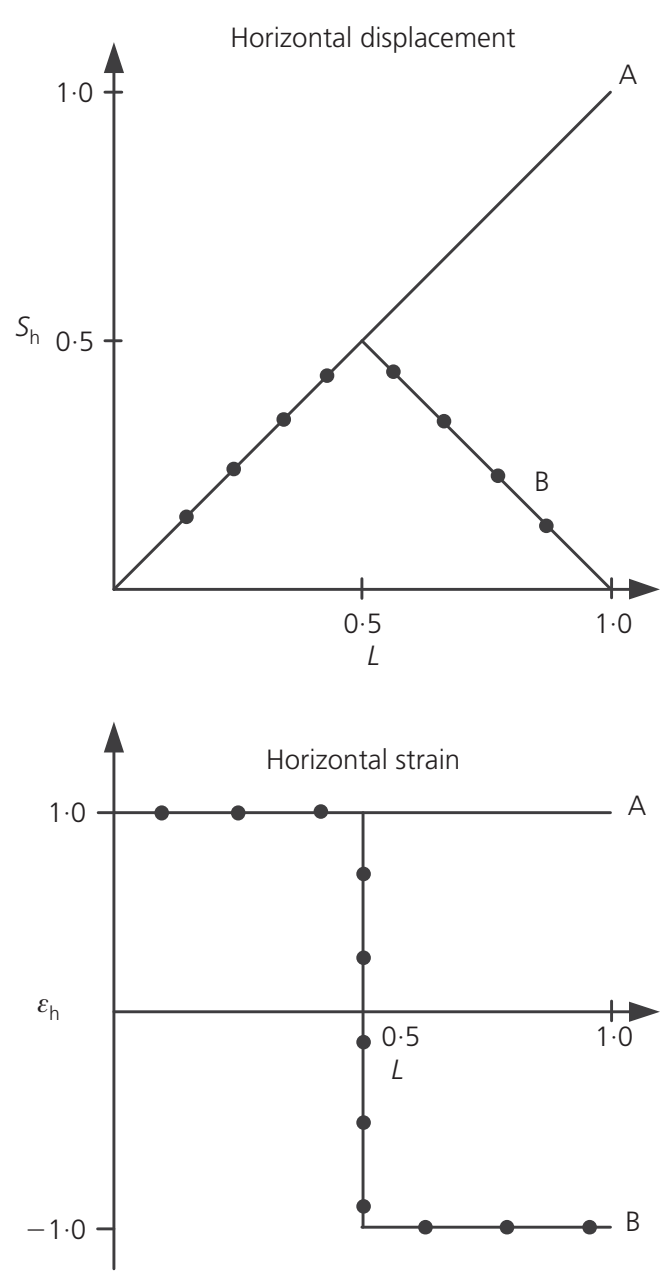

\section{REFERENCES}

Liu Q and Ma J (2013) Analytical model for beams on elastic foundations considering the coupling of horizontal and vertical displacements. Journal of Engineering Mechanics 139(12): 1757-1768.
Namazi E and Mohamad H (2010) Potential damage assessment in buildings undergoing tilt. Proceedings of the Institution of Civil Engineers - Geotechnical Engineering 166(4): 365372, http://dx.doi.org/10.1680/geng.10.00132. 